\title{
Relationship Between Asymmetries in Striatal Dopamine Release and the Direction of Amphetamine-Induced Rotation During the First Week Following a Unilateral 6-OHDA Lesion of the Substantia Nigra
}

\author{
TERRY E. ROBINSON, MAURA NOORDHOORN, EMILY M. CHAN, ZOLTAN MOCSARY, \\ DIANNE M. CAMP, AND IAN Q. WHISHAW \\ Department of Psychology and Neuroscience Program, The University of Michigan, Ann Arbor, Michigan \\ 48104-1687 (T.E.R., M.N., E.M.C., Z.M., D.M.C.) and Department of Psychology, University of Lethbridge, \\ Lethbridge AB, Canada (I.Q.W.)
}

\section{KEY WORDS Microdialysis, Recovery, Caudate nucleus, Striatum}

ABSTRACT In animals with a large unilateral 6-hydroxydopamine (6-OHDA) lesion of the nigrostriatal dopamine (DA) system the traditional "rotational behavior model" states that amphetamine will induce circling behavior towards the denervated striatum (ipsiversive), that is, away from the side where there is greater amphetamine-stimulated DA release and greater DA receptor stimulation. It is puzzling, therefore, why amphetamine induces contraversive rotation in rats tested 4 days after a unilateral 6-OHDA lesion, despite a 90-95\% loss of the dopaminergic input to the striatum by this time. Rats reverse their direction of amphetamine-induced rotation by 8 days post-lesion and turn in the ipsiversive direction thereafter. To try and resolve this paradox, bilateral striatal microdialysis was used to estimate the effects of amphetamine on DA neurotransmission on Day 4 and Day 8 following a large unilateral 6-OHDA lesion of the substantia nigra. On Day 4 post-lesion, amphetamine produced a moderate (around 50\% of control) increase in the extracellular concentration of DA in the denervated striatum. This amphetamine-releasable pool of DA was exhausted by a single amphetamine challenge, because a second injection of amphetamine given $3 \mathrm{~h}$ after the first did not produce a comparable increase in DA. It is suggested that on Day 4 post-lesion the amount of DA released by amphetamine in the denervated striatum is sufficient to produce greater DA receptor stimulation on that side, because of DA receptor supersensitivity, and this leads to contraversive rotation. On Day 8 post-lesion, amphetamine induced DA release in the intact striatum but had no effect on extracellular DA in the denervated striatum (DA was nondetectable). On Day 8, therefore, DA receptor stimulation would be greatest in the intact striatum, leading to ipsiversive rotation. In conclusion, it is suggested that the seemingly paradoxical reversal in the direction of amphetamine-induced rotation that occurs over the first week following a unilateral 6-OHDA lesion is consistent with the traditional rotational model, and is due to time-dependent changes in the ability of amphetamine to release DA in the denervated striatum. 1994 Wiley-Liss, Inc.

\section{INTRODUCTION}

Drug-induced behavioral asymmetries seen in animals with unilateral damage to the nigrostriatal DA system are among the most extensively studied behavioral phenomena in neuroscience. The "rotational behavior model," first described by Ungerstedt (1971a,b; Ungerstedt and Arbuthnott, 1970), provides a generally accepted rule regarding the effects of dopaminergic drugs on behavioral asymmetries and, in particular, on rotational or turning behavior. In animals with unilat- eral destruction of the nigrostriatal DA system, drugs that act to release DA, such as amphetamine, produce turning towards the denervated striatum (ipsiversive). Drugs that act as DA receptor agonists, such as apomorphine, produce turning away from the denervated

\footnotetext{
Received June 14, 1993; accepted in revised form October 26, 1993.

Address correspondence to Dr. Terry E. Robinson, Neuroscience Laboratory Building, The University of Michigan, 1103 East Huron Street, Ann Arbor, MI
} 48104-1687. 
striatum (contraversive). The rule, therefore, is that animals turn away from the striatum with the greatest DA receptor stimulation, which in the case of amphetamine is on the intact side (where intact presynaptic terminals can release DA), and in the case of DA receptor agonists is on the denervated side (where DA receptors are supersensitive).

There are, however, apparent exceptions to this rule. For example, it has been known since Ungerstedt's (1971) original studies that for 24-36 h after a unilateral 6-OHDA lesion amphetamine often induces contraversive rotation (Oberlander et al., 1980, as well). This is usually explained in terms of a transient accumulation of DA during the degenerative process. Of more interest are reports that in rats with a very large 6-OHDA lesion, amphetamine can induce contraversive rotation for up to 6 days post-lesion (Carey, 1992; Lynch and Carey, 1989; Mintz et al., 1986), despite an almost complete loss of the dopaminergic input to the striatum within 3-4 days post-lesion (Altar et al, 1984). By 3-4 days post-lesion there is already a $>90$ 95\% decrease in DA histofluorescence (Hökfelt and Ungerstedt, 1973), in the postmortem tissue content of DA (Altar et al., 1984; Carey, 1992; Neve et al., 1982; Staunton et al., 1981), in DA uptake sites (Altar et al., 1987), and in boutons with small granular vesicles (Hökfelt and Ungerstedt, 1973).

There are two possible interpretations of this phenomenon. First, for 4-6 days after a unilateral 6-OHDA lesion amphetamine may not induce turning towards the striatum with the greatest DA receptor stimulation. If this is true the basic tenet of the rotational behavior model would be violated. This could have important implications, because the model is widely used to estimate, for example, the actions of drugs on DA systems, the degree of recovery of function following DA depletion, and the effectiveness of neural tissue grafts (Zigmond et al., 1990). A second possibility is that at 4 days post-lesion amphetamine does result in greater DA receptor stimulation in the denervated striatum. If this is true, there must be as of yet unidentified time-dependent changes in the ability of amphetamine to release DA, despite a $>90-95 \%$ lesion of the nigrostriatal DA system. Carey (1992) suggested, for example, there may be a small residual amphetamine-releasable pool of DA that persists for 4-6 days post-lesion, and that DA released from this pool is sufficient to induce contraversive rotation because of its action on supersensitive DA receptors. The purpose of the present study was to test this hypothesis.

\section{METHODS \\ Experiment 1}

\section{Subjects and surgical procedures}

Adult female rats (Holtzman Sprague-Dawley) weighing approximately $225 \mathrm{~g}$ were housed individu- ally in wire mesh cages in a room maintained on a 14:10 h light:dark cycle (lights on at 08:00), with free access to food and water. The animals were pretreated with 5 $\mathrm{mg} / \mathrm{kg}$ of atropine methyl nitrate, anesthetized with 30 $\mathrm{mg} / \mathrm{kg}$ of sodium pentobarbital (i.p.), supplemented with methoxyflurane, and then using standard stereotaxic procedures, one 23 gauge stainless steel guide cannula was positioned on the dural surface above the nigrostriatal bundle (coordinates: $3.0 \mathrm{~mm}$ posterior to bregma, $1.8 \mathrm{~mm}$ lateral, and $1.0 \mathrm{~mm}$ ventral from skull surface; Paxinos and Watson, 1986). The guide cannula was fixed in place with dental cement and jeweler's screws attached to the skull, and closed with a stainless steel stylet. After recovery from the anaesthetic the animals were returned to their home cages.

\section{6-OHDA lesions}

At least 2 days following surgery the animals were pretreated with $15 \mathrm{mg} / \mathrm{kg}$ desipramine- $\mathrm{HCl}$, and between 30 and 60 min later a 30 gauge injection cannula was inserted into the guide cannula to the level of the nigrostriatal bundle. An infusion pump was used to infuse $8 \mu \mathrm{g}$ of 6-hydroxydopamine $\mathrm{HBr}$ (6-OHDA) dissolved in $4 \mu \mathrm{l}$ of vehicle $(0.9 \% \mathrm{NaCl}$ solution containing $0.1 \mathrm{mg} / \mathrm{ml}$ ascorbic acid) over a period of $8 \mathrm{~min}$. Following the infusion the injection cannula was left in place for $2 \mathrm{~min}$ before it was removed and the stylet was replaced. The animals were not anaesthetized during this procedure. This day (the day of the lesion) was defined as Day 0.

\section{Test procedure}

Two days following the 6-OHDA lesion (post-lesion) animals were observed for spontaneous rotational behavior for $10 \mathrm{~min}$ on a small $\left(12^{\prime \prime} \times 12^{\prime \prime}\right)$ elevated platform, and then were returned to their home cage. Four days post-lesion each animal was placed in an automated hemispherical rotometer described previously (McFarlane et al., 1992). This device recorded the number of quarter $\left(90^{\circ}\right)$ turns during each $5 \mathrm{~min}$ interval. These data were converted to full rotations, which are defined as four consecutive $90^{\circ}$ turns in the same direction, and net rotations, which are defined as full rotations in the dominant direction minus full rotations in the nondominant direction. Following a 15 min habituation period animals received an i.p. injection of 1.5 $\mathrm{mg} / \mathrm{kg} d$-amphetamine sulfate (weight of the salt) and rotational behavior was recorded for $1 \mathrm{~h}$. They were then replaced in their home cages, until this procedure was repeated, on Days 6, 8, and 10 post-lesion. Two weeks post-lesion the animals were again tested for rotational behavior, but now received $0.05 \mathrm{mg} / \mathrm{kg}$ of apomorphine $\mathrm{HCl}$ (weight of salt). This latter test was done to determine whether the animals had a nearly complete depletion of striatal DA, because animals with less than a 90-95\% DA depletion do not respond to this dose of apomorphine (Marshall and Ungerstedt, 1977). 
To estimate the size of the lesion, and to confirm the reliability of the apomorphine test, the animals were killed 3 weeks post-lesion and striatal samples obtained for postmortem tissue assay.

To determine the extent of DA depletion in postmortem tissue specifically on Day 4 and Day 8 post-lesion, two additional independent groups of rats were given a 6-OHDA lesion, as described above, and striatal tissue was obtained at these points in time. These latter animals did not undergo any behavioral testing.

\section{Tissue assay}

Animals were killed by decapitation and their brains were removed and placed in ice-cold saline. After the brain cooled ( $30-45 \mathrm{sec}$ ), it was placed in a chilled cutting block and brain slices were obtained as described by Heffner et al. (1980). Using a $2 \mathrm{~mm}$ tissue punch a sample from the corpus of each striatum was taken, weighed, and placed into a tube containing $0.05 \mathrm{~N}$ perchloric acid and dihydroxybenzylamine (internal standard). The samples were homogenized and centrifuged and the supernatant was assayed by HPLC-EC, using procedures similar to those described previously (Robinson et al., 1987).

\section{Experiment 2}

The subjects and surgical procedures were the same as are described for Experiment 1, except in addition to implantation of a chronic guide cannula for the 6-OHDA lesion, a guide cannula was also placed on the dural surface above each striatum (i.e., bilaterally: coordinates, $0.6 \mathrm{~mm}$ anterior to bregma, $2.8 \mathrm{~mm}$ lateral, and $1 \mathrm{~mm}$ ventral from the skull surface). At least 3 days following surgery 15 animals received a $6-\mathrm{OHDA}$ lesion, as described above, and 6 control animals received a "sham lesion" (i.e., the injection cannula was simply lowered and left in place for $10 \mathrm{~min}$ ). Of the rats given a 6-OHDA lesion, eight underwent dialysis on Day 4 post-lesion and seven underwent dialysis on Day 8 post-lesion. Control animals were tested with each of these groups, using the following procedures.

The day prior to microdialysis testing, animals were lightly anaesthetized with ether and a dialysis probe was inserted into the guide cannula overlying each striatum. The exposed surface of the dialysis membrane was $4 \mathrm{~mm}$ long, and was positioned to sample the entire dorso-ventral extent of the striatum (see Fig. 4 in Robinson and Whishaw, 1988). The dialysis probes and procedures have been described in detail previously (Robinson and Camp, 1991). Each rat was then placed in a hemispherical testing chamber equipped for both microdialysis sampling and the automated measurement of rotational behavior. The probes were perfused with a perfusion solution containing $145 \mathrm{mM} \mathrm{NaCl}, 2.7 \mathrm{mM}$ $\mathrm{KCl}, 1.2 \mathrm{mM} \mathrm{CaCl}_{2}, 1.0 \mathrm{mM} \mathrm{MgCl}$, and $0.2 \mathrm{mM}$ ascorbic acid, pH 7.3 (Moghaddam and Bunney, 1989), at a flow rate of $0.3 \mu \mathrm{l} / \mathrm{min}$. The following day, the pump speed was increased to $1.5 \mu \mathrm{l} / \mathrm{min}$, and after at least a 30 min equilibration period, a minimum of three 20 minute basal samples of dialysate were collected. Following this, each rat was given an injection of $1.5 \mathrm{mg} / \mathrm{kg}$ of $d$-amphetamine sulfate (i.p.), and ten additional 20 min samples of dialysate were collected. At the same time, rotational behavior was monitored using the device described above. At the completion of the experiment, the dialysis probes were removed, the stylets were replaced, and the rats were returned to their home cages.

Ten days post-lesion, animals with a 6-OHDA lesion were screened for apomorphine-induced rotation, as described above. Only animals that made at least 100 contraversive rotations within the $30 \mathrm{~min}$ test session were included in the experiment, to insure a homogenous group with $>95 \%$ DA depletions. Following this, animals were given an overdose of sodium pentobarbital, perfused through the heart with $0.9 \%$ saline followed by $10 \%$ formalin in saline, and the brains obtained for histological analysis. Sections of each brain were obtained through the striatum, mounted, stained with cresyl violet, and examined to reconstruct the track formed by each dialysis probe. Only animals with at least $75 \%$ of the dialysis surface of each probe located within the corpus of the striatum were included in the experiment.

\section{Experiment 3}

The procedures for this experiment were the same as for Experiment 2, with the following modifications: 1) all animals were tested only 4 days following a unilateral 6-OHDA lesion $(n=8)$, and 2) after collecting basal dialysate all animals received two successive injections of $1.5 \mathrm{mg} / \mathrm{kg}$ of $d$-amphetamine, $200 \mathrm{~min}$ apart, and ten 20 min samples of dialysate were collected following each injection.

\section{RESULTS \\ Experiment 1}

The direction and rate of amphetamine-induced rotation seen in animals tested 4,6,8, and 10 days following a unilateral 6-OHDA lesion is illustrated in Figure 1. Four days post-lesion amphetamine produced rotation predominantly away from the denervated striatum (contraversive) in every animal. By 6 days post-lesion, animals showed predominately contraversive rotation for the first $15 \mathrm{~min}$ of the test session and then switched direction and showed predominately ipsiversive rotation for the remainder of the test session (time course data not shown). Finally, by 8 and 10 days post-lesion, amphetamine produced ipsiversive rotation exclusively in every animal.

It needs to be emphasized, however, that during the 15 min habituation period, prior to amphetamine administration, spontaneous rotation was almost exclusively in the ipsiversive direction on all days post- 


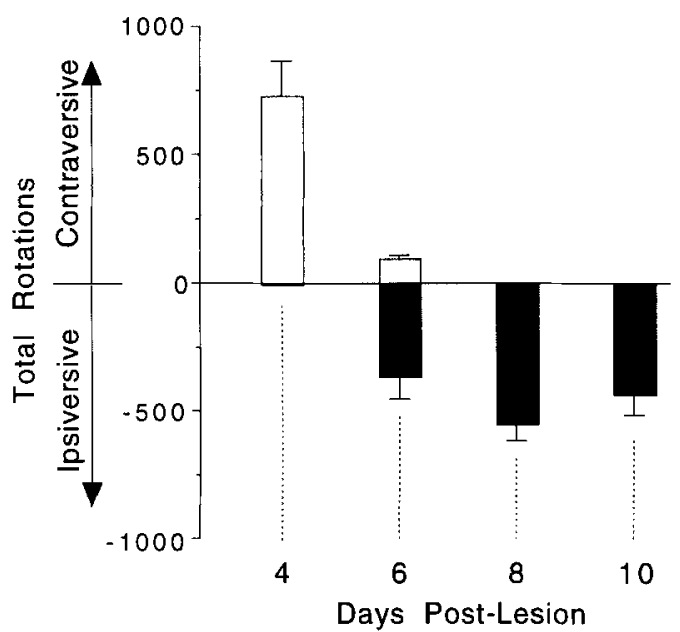

Fig. 1. The mean (+SEM) number of total rotations $\left(360^{\circ}\right.$ turns) induced by $1.5 \mathrm{mg} / \mathrm{kg}$ of $d$-amphetamine on Days $4,6,8$, and 10 following a unilateral 6-OHDA lesion of the substantia nigra $(n=5)$. On Day 4 , every animal turned exclusively away from the denervated striatum (contraversive). On Day 6 , animals made rotations in both the contraversive and ipsiversive directions. On Days 8 and 10 every animal turned exclusively towards the denervated striatum; that is, in the ipsiversive direction. Positive numbers were arbitrarily defined as contraversive rotations and negative numbers as ipsiversive rotations.

TABLE I. The mean ( $\pm S E M$ ) concentration of dopamine (ng/mg wet tissue weight) in postmortem tissue samples obtained from the intact or denervated striatum of rats 4 or 8 days following a unilateral 6-OHDA lesion

\begin{tabular}{lcccc}
\hline & $\mathrm{N}$ & Intact side & Denervated side & \% Depletion \\
\hline Day 4 & 5 & $13.2 \pm 0.42$ & $1.32 \pm 0.26^{1}$ & $90.1 \pm 1.95^{2}$ \\
Day 8 & 4 & $12.4 \pm 0.78$ & $0.57 \pm 0.55^{1}$ & $95.2 \pm 4.62^{2}$ \\
\hline
\end{tabular}

${ }^{1}$ Differs from the intact side.

${ }^{2}$ Note that this may underestimate lesion size because animals could not be screened for apomorphine-induced rotation, as in the other experiments (see text).

lesion. For example, on Day 4 post-lesion the total number of spontaneous habituation period rotations summed over all 6-OHDA-treated animals was 0 in the contraversive direction vs. 26 in the ipsiversive direction; on Day 6 the values were 0 and 44; on Day 8, 1 and 87; and on Day 10, 0 and 109, respectively.

Two weeks post-lesion all animals were screened for apomorphine-induced rotation, and only those that showed over 100 contraversive rotations in a $30 \mathrm{~min}$ test session were used. Postmortem tissue analysis of the animals that passed the apomorphine "screen" revealed the average $( \pm$ SEM) depletion of striatal DA was $99.5 \pm 0.19 \%$ (relative to the intact striatum).

An independent group of animals received a unilateral 6-OHDA lesion and half were killed on Day 4 postlesion and the other half were killed on Day 8 postlesion, to determine the extent of DA depletion at these times. Table I shows that in the denervated striatum, DA was already depleted by over $90 \%$ by Day 4 (intact side differs from denervated side, $\mathrm{U}=0, P<0.01$; for Day $8, \mathrm{U}=0, P<0.03$ ). The percent DA depletion on
Day 4 did not differ significantly from that on Day 8 $(\mathrm{t}=1.12, P=0.29)$.

\section{Experiment 2}

A total of 21 animals received a unilateral 6-OHDA lesion or a control operation and then underwent microdialysis testing. Of these, five animals did not show apomorphine-induced rotation on Day 10 post-lesion and were dropped from the experiment. An additional two animals were dropped because histological analysis revealed that they had at least one dialysis probe with less than $75 \%$ of its surface area within the striatum. This resulted in three final groups: 1) a control group with no lesion $(n=4), 2)$ a group with a 6-OHDA lesion tested 4 days post-lesion $(n=5)$, and 3 ) a group with a 6 -OHDA lesion tested 8 days post-lesion $(n=5)$. In control animals each probe was considered an independent sample, resulting in $n=8$ determinations for this group.

\section{Basal dialysate}

Table II shows the average basal concentrations of DA, DOPAC, HVA, and 5-HIAA in striatal dialysate obtained from control animals, and from both the intact and denervated striata of animals tested 4 or 8 days post-lesion. All measures of basal DA neurotransmission indicated that the animals given 6-OHDA had a very large lesion. For example, in animals tested on Day 4 post-lesion, DA in dialysate obtained from the denervated striatum was only $21 \%$ of control, DOPAC was $5 \%$ of control, and HVA was $7 \%$ of control. In animals tested on Day 8 post-lesion these values were $<1 \%, 1 \%$, and $2 \%$ of control, respectively. It should be noted, however, that in animals tested on Day 4 the DA values underestimate lesion size, because the means shown in Table II were calculated using only values from animals with detectable DA. DA was nondetectable in 2/5 animals tested on Day 4 post-lesion, and in $5 / 5$ animals tested on Day 8 post-lesion. The only other significant effect was between control 5-HIAA levels and 5-HIAA levels in the denervated striatum of rats tested 4 days post-lesion (Table II).

\section{Effects of amphetamine}

Following the collection of basal samples, all animals received an injection of $1.5 \mathrm{mg} / \mathrm{kg} d$-amphetamine, and Figure 2 shows the number of net rotations induced by amphetamine in each of the three groups. Control animals showed only very low rates of rotation. All animals tested on Day 4 post-lesion showed vigorous contraversive rotational behavior. All animals tested on Day 8 post-lesion showed vigorous ipsiversive rotation. This replicates the reversal in direction of rotational behavior between Day 4 and Day 8 observed in Experiment 1 .

Figure 3 shows the effects of amphetamine on the concentration of DA in dialysate collected simultaneously from the denervated striatum (Fig. 3A) and the 
ABLE II. Basal dialysate values (mean $\pm S E M$ ) in $\mathrm{pg} / \mathrm{Al}$ (corrected

\begin{tabular}{|c|c|c|c|c|c|}
\hline & $\mathrm{N}$ & DA & DOPAC & HVA & 5-HIAA \\
\hline Control & 8 & $1.39 \pm 0.22$ & $805 \pm 79.3$ & $587 \pm 86.5$ & $197 \pm 13.9$ \\
\hline \multicolumn{6}{|l|}{ Day 4} \\
\hline (Intact) & 5 & $\begin{array}{c}1.35 \pm 0.25 \\
(97 \%)\end{array}$ & $\begin{array}{c}732 \pm 90.4 \\
(91 \%)\end{array}$ & $\begin{array}{c}718 \pm 102.5 \\
(122 \%)\end{array}$ & $\begin{array}{c}210 \pm 25.1 \\
(107 \%)\end{array}$ \\
\hline (Denervated) & 5 & $\begin{array}{l}0.29 \pm 0.11^{2} \\
(21 \%) 2 \mathrm{ND}\end{array}$ & $\begin{array}{c}39.8 \pm 6.07^{2} \\
(5 \%)\end{array}$ & $\begin{array}{c}43.1 \pm 6.37^{2} \\
(7 \%)\end{array}$ & $\begin{array}{c}138 \pm 21.2^{3} \\
(70 \%) \\
\end{array}$ \\
\hline \multicolumn{6}{|l|}{ Day 8} \\
\hline (Intact) & 5 & $\begin{array}{c}1.93 \pm 0.65 \\
(139 \%)\end{array}$ & $\begin{array}{c}784 \pm 88.6 \\
(97 \%)\end{array}$ & $\begin{array}{c}689 \pm 171 \\
(117 \%)\end{array}$ & $\begin{array}{c}230 \pm 35.9 \\
(117 \%)\end{array}$ \\
\hline (Denervated) & 5 & $\begin{array}{l}5 \mathrm{ND}^{2} \\
(<1 \%)\end{array}$ & $\begin{array}{c}7.49 \pm 0.11^{2} \\
(1 \%) 3 \mathrm{ND}\end{array}$ & $\begin{array}{c}8.82 \pm 5.74^{2} \\
(2 \%) 3 \mathrm{ND}\end{array}$ & $\begin{array}{c}173 \pm 26.0 \\
(88 \%)\end{array}$ \\
\hline
\end{tabular}

${ }^{1}$ Numbers in parentheses indicate the experimental mean expressed as a percent of the control mean, and the number of animals in which values were nondetectable is indicated by the number followed by ND where applicable.

${ }^{2}$ Differs significantly from the intact side and from control $(\mathrm{U}=0$ to $4, P<0.01-0.001)$.

${ }^{3}$ Differs significantly from control $(\mathrm{U}=\mathbf{4}, P<0.01)$.

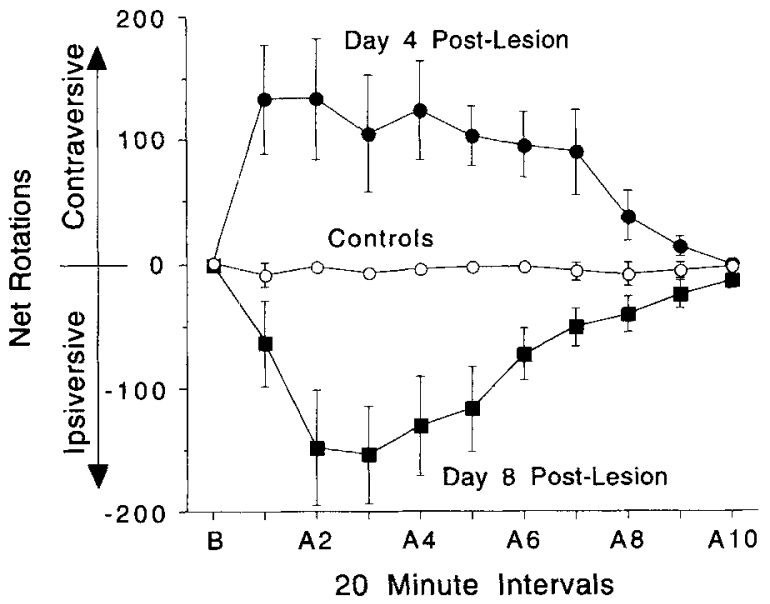

Fig. 2. The mean ( $\pm \mathrm{SEM})$ number of net rotations per 20 min interval induced by $1.5 \mathrm{mg} / \mathrm{kg}$ of $d$-amphetamine in animals undergoing microdialysis. There are three independent groups: 1) a group with a unilateral 6-OHDA lesion that was tested on Day 4 post-lesion $(n=5$; closed circles), 2) a group with a unilateral 6-OHDA lesion group that was tested on day 8 post-lesion ( $n=5$; closed squares), and 3 ) a control group ( $n=4$; open circles). On Day 4 post-lesion, all animals with a 6-OHDA lesion turned predominantly in the contraversive direction. On Day 8, all animals with a 6-OHDA lesion turned predominantly in the ipsiversive direction. Control animals showed only very low rates of rotational behavior with no significant directional bias. Positive numbers were arbitrarily defined as contraversive rotations and negative numbers as ipsiversive rotations. $\mathrm{B}$, baseline; $\mathrm{A1}$ to $\mathrm{A10}$, successive 20 min intervals following amphetamine. All group comparisons were highly significant (two-way ANOVAs).

intact striatum (Fig. 3B), as well as from control animals, as they engaged in the rotational behavior summarized in Figure 2. Amphetamine produced a large increase in the concentration of DA in dialysate obtained from the intact striatum of all animals, and there were no significant group differences (Fig. 3B). In animals tested 4 days post-lesion amphetamine produced a moderate increase in DA on the denervated side (Fig. 3A), although this was significantly less than on the intact side, or in control animals. In animals tested 8 days post-lesion, DA was nondetectable in the denervated striatum at all points in time (Fig. 3A).
Figure 4A shows the effects of amphetamine on the concentration of DOPAC in dialysate collected simultaneously from the intact and denervated striata of rats with a 6-OHDA lesion, and from control animals. In control animals, and in the intact striatum of animals with a 6-OHDA lesion, amphetamine produced the expected decrease in DOPAC concentrations. In the denervated striatum of animals tested 8 days post-lesion DOPAC was detectable in only two of five animals, and therefore, no effect of amphetamine was evident. In the denervated striatum of animals tested 4 days postlesion, however, amphetamine produced a small, but highly significant, increase in both DOPAC and HVA. This is best illustrated by the inset in Figure 4 (4B), in which the vertical scale is expanded.

\section{Experiment 3}

Figure 5 shows the effects of two successive injections of $1.5 \mathrm{mg} / \mathrm{kg}$ of $d$-amphetamine on rotational behavior. Following the first injection of amphetamine all animals showed contraversive rotation for approximately $1.5 \mathrm{~h}$, after which time they started to show low levels of ipsiversive rotation. Following the second injection of amphetamine all animals showed predominantly ipsiversive rotation.

Figure 6 shows the effects of amphetamine on the concentration of DA in dialysate collected from the intact and denervated striata, as animals engaged in the behavior summarized in Figure 5 . Both injections of amphetamine produced an equivalent large increase in the concentration of DA in dialysate collected from the intact striatum. In the denervated striatum, however, the first injection of amphetamine produced a modest but significant increase in DA, but the second injection of amphetamine had very little effect.

Figure 7 shows the effects of amphetamine on the concentration of DOPAC in dialysate collected simultaneously from the intact and denervated striata. In the intact striatum amphetamine produced the expected decrease in DOPAC. By the end of the first injection period DOPAC concentrations were returning to base- 

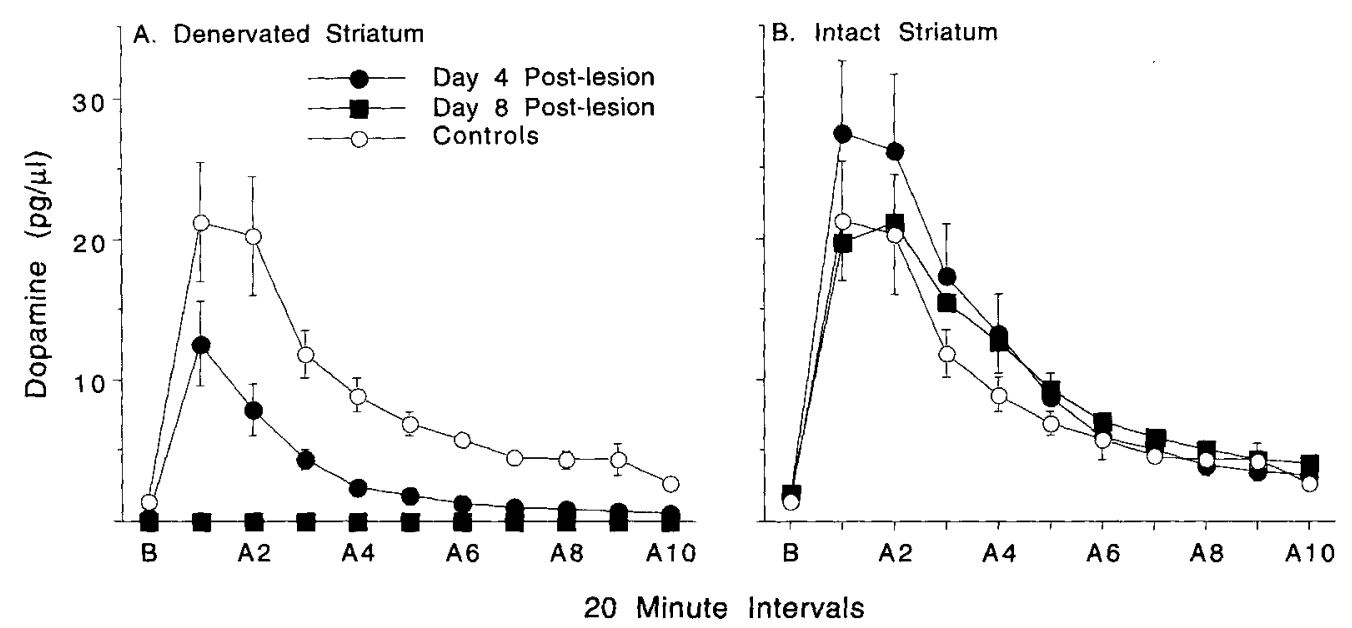

Fig. 3. The mean ( $\pm S E M)$ concentration of $\mathrm{DA}(\mathrm{pg} / \mu \mathrm{l}$; corrected for recovery) in 20 min fractions of striatal dialysate collected before (B, basal) and following $1.5 \mathrm{mg} / \mathrm{kg}$ of $d$-amphetamine (A1-A10), in control rats ( $n=8$ determinations) and rats tested either 4 days $(n=5)$ or 8 days $(\mathrm{n}=5$ ) following a unilateral 6-OHDA lesion. A: Denervated Striatum. Amphetamine induced a significant increase in extracellular DA in the striatum of control rats, and in the denervated striatum of rats tested on Day 4 post-lesion (for the Day 4 post-lesion group: one-way ANOVA with repeated measures, $\mathrm{F}=4.52, P<0.001$ ). The amount of amphetamine-stimulated DA release in the denervated striatum of animals tested 4 days post-lesion was significantly less than in their intact striatum, and in controls (Day 4, denervated striatum vs. controls, $\mathrm{F}=9.54, P<0.01$; Day 4 , denervated striatum vs. Day 4 , intact striatum, $F=7.29, P<0.001$ ). In animals tested 8 days post-lesion amphetamine failed to release DA (DA was nondetectable both before and after amphetamine administration). B: Intact Striatum. Amphetamine produced a large, statistically significant increase in extracellular DA in all groups, and there were no significant group differences (two-way ANOVA). Note that the same control values shown in A are simply replotted in $\mathrm{B}$ to facilitate comparisons. line, but they declined again following the second injection of amphetamine. In the denervated striatum, however, the first injection of amphetamine produced a small, but highly significant, increase in DOPAC, and this was not seen following the second injection of amphetamine (see inset in Fig. 7).

\section{DISCUSSION}

This study confirms previous reports that rats with a large unilateral 6-OHDA lesion of the substantia nigra reverse their direction of amphetamine-induced rotational behavior between 4 and 8 days post-lesion (Carey, 1992; Lynch and Carey, 1989; Mintz et al., 1986). For 4-6 days post-lesion, amphetamine produces contraversive rotational behavior. By 8 days post-lesion rats reverse their direction of amphetamine-induced rotation, and turn in the ipsiversive direction thereafter.

According to the traditional rotational behavior model, animals should not turn in the contraversive direction following amphetamine administration (Ungerstedt, 1971a, 1971b; Ungerstedt and Arbuthnott, 1970), at least if the striatum on the side with a lesion is denervated of DA terminals. There is considerable evidence, however, suggesting that the striatum ipsilateral to a 6-OHDA lesion is already denervated of 90 $95 \%$ of its dopaminergic input within $3-4$ days postlesion. For example, in this, and other studies, the postmortem tissue content of DA was reduced by over 90\% by Day 4 post-lesion (Carey, 1992; Mishra et al., 1980; Neve et al., 1984; Staunton et al., 1981), and this is thought to provide a good index of DA terminal density (Altar et al., 1987). Others have also reported that within 2-4 days following a 6-OHDA lesion there is already a $>90-95 \%$ decrease in the density of DA uptake sites (Altar et al., 1987), in catecholamine histofluorescence (Hökfelt and Ungerstedt, 1973), and in the number of boutons containing small granular vesicles (Hökfelt and Ungerstedt, 1973). Furthermore, in the present study, basal DOPAC concentrations in dialysate from the denervated striatum were reduced by $95 \%$ within 4 days post-lesion, indicative of a massive loss of dopaminergic input at this time. There was a further decrease in DOPAC of around $4 \%$ between Day 4 and Day 8 , which is consistent with postmortem tissue measures reported here and elsewhere (Carey, 1992). Finally, during the first week post-lesion rats with a unilateral 6-OHDA lesion show marked behavioral deficits, including spontaneous ipsiversive rotational behavior and contralateral sensorimotor neglect (Altar et al., 1984; present study). [As an aside, it is worth noting that the basal concentration of DOPAC in dialysate probably provides a more accurate index of DA terminal density in this situation than does DA itself, because DOPAC is formed primarily intraneuronally, independent of DA release (Kuczenski and Segal, 1989; Zetterström et al., 1988), and because DOPAC is not influenced by the same compensatory neuroadaptations that serve to normalize the extracellular concentration of DA (Castañeda et al., 1990; Robinson et al., 1990; Robinson and Whishaw, 1988; Zigmond et al., 1990).] 


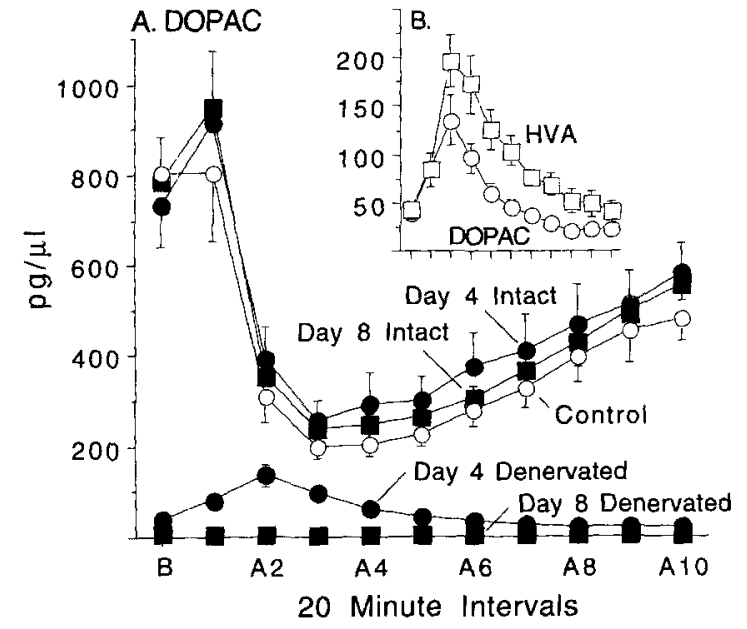

Fig. 4. A: The mean ( \pm SEM) concentration of DOPAC $(\mathrm{pg} / \mu \mathrm{l}$; corrected for recovery) in $20 \mathrm{~min}$ fractions of striatal dialysate before ( $B$ basal) and following $1.5 \mathrm{mg} / \mathrm{kg}$ of $d$-amphetamine (A1-A10), in control rats and rats tested either 4 or 8 days following a unilateral 6-OHDA lesion. The 6-OHDA lesion resulted in a marked decrease in the basal concentration of DOPAC (compare the basal values for the intact striatum or control animals, to the basal values for the denervated striatum; also see Table II). In control rats (open circles), and in the intact striatum of animals tested on either Day 4 (filled circles) or Day 8 (filled squares) post-lesion, amphetamine produced the expected decrease in extracellular DOPAC, and there were no group differences (two-way ANOVA). In the denervated striatum of animals tested 8 days post-lesion DOPAC was nondetectable. Interestingly, in the denervated striatum of rats tested 4 days post-lesion, amphetamine induced a small, but highly significant, increase in the concentration of DOPAC in dialysate (one-way ANOVA with repeated measures $\mathrm{F}=21.0, P<0.001$ ). These latter values are replotted in the inset (B) with an expanded vertical scale to better illustrate the magnitude of the amphetamine-induced increase in DOPAC. In addition, the inset shows that in these animals amphetamine also produced a significant increase in the concentration of HVA in dialysate $(F=15.2$, $P<0.001$ )

Thus, despite what seems to be an almost complete (>90-95\%) loss of the dopaminergic input to the striatum by Day 4 post-lesion, amphetamine produces vigorous contraversive rotation. According to the traditional rotational behavior model, therefore, amphetamine must produce sufficient DA release in the denervated striatum to result in greater DA receptor stimulation on that side than on the intact side. Furthermore, the degree of DA terminal denervation increases by only a few percent between 4 and 8 days post-lesion, but the direction of amphetamine-induced rotation reverses, suggesting the side with greater DA receptor stimulation must also reverse. The microdialysis findings support this interpretation, because between 4 and 8 days after a 6-OHDA lesion there was a marked change in the ability of amphetamine to elevate the extracellular concentration of DA in the denervated striatum. On Day 4 post-lesion amphetamine produced a moderate increase in the concentration of DA in dialysate obtained from the denervated striatum, which was about $50 \%$ of that seen in the intact striatum or in control animals. By Day 8 post-lesion, however, amphetamine had no measurable effect on extracellular DA in the denervated striatum; DA was nondetectable both before and after amphetamine administration.

Obviously, the asymmetry in amphetamine-stimulated DA release alone does not explain the direction of rotation on Day 4 post-lesion, because the absolute amount of DA released in the denervated striatum was less than in the intact striatum. There is evidence to suggest, however, that by Day 4 post-lesion DA receptors on the denervated side are already supersensitive. For example, animals are behaviorally hypersensitive to DA receptor agonists within 2-3 days after a 6-OHDA lesion (Costall et al., 1976; Neve et al., 1982; Staunton et al., 1981; Ungerstedt, 1971), and although there is not an increase in DA receptor binding in vitro until a few weeks post-lesion, in vivo ${ }^{3} \mathrm{H}$-spiroperidol binding is significantly elevated by 4 days post-lesion (Neve et al., 1982). In addition, DA can probably diffuse for longer distances in the denervated striatum. In the intact striatum DA does not diffuse for any significant distance from release sites, because of a very efficient uptake system (Doucet et al., 1986; Ewing and Wightman, 1984). Within 2-4 days following a 6-OHDA lesion, however, most of the presynaptic uptake sites are lost (Altar et al., 1987), and the time taken to clear DA is greatly increased (Keller et al., 1988; van Horne et al., 1992; Wightman and Zimmerman, 1990). Thus, DA released in a denervated striatum diffuses farther than in an innervated striatum (Doucet et al., 1986; Wightman and Zimmerman, 1990), and presumably has a greater opportunity to interact with distant supersensitive DA receptors.

We suggest, therefore, that on Day 4 post-lesion the amount of DA released by amphetamine in the denervated striatum is sufficient to produce greater $D A$ receptor stimulation on that side, because this DA acts on supersensitive DA receptors; and the result is contraversive rotation (Carey, 1992, as well). By 8 days postlesion, DA receptors in the denervated striatum may be even more supersensitive, but because amphetamine now fails to induce any DA release, DA receptor stimulation is greater on the intact side, where amphetamine does release DA, and the result is ipsiversive rotation.

The source of the amphetamine-releasable pool of DA evident on Day 4 is not known. It does not appear to be a rapidly renewable pool, however, because it was exhausted by a single injection of amphetamine. Two successive injections of amphetamine $200 \mathrm{~min}$ apart produced an equivalent large increase in DA in the intact striatum, but only the first injection produced DA release in the denervated striatum, and animals reversed their direction of rotational behavior between the first and second injections. This is consistent with the behavioral studies of Mintz et al. (1986), who reported that vigorous contraversive rotation only occurred fol- 


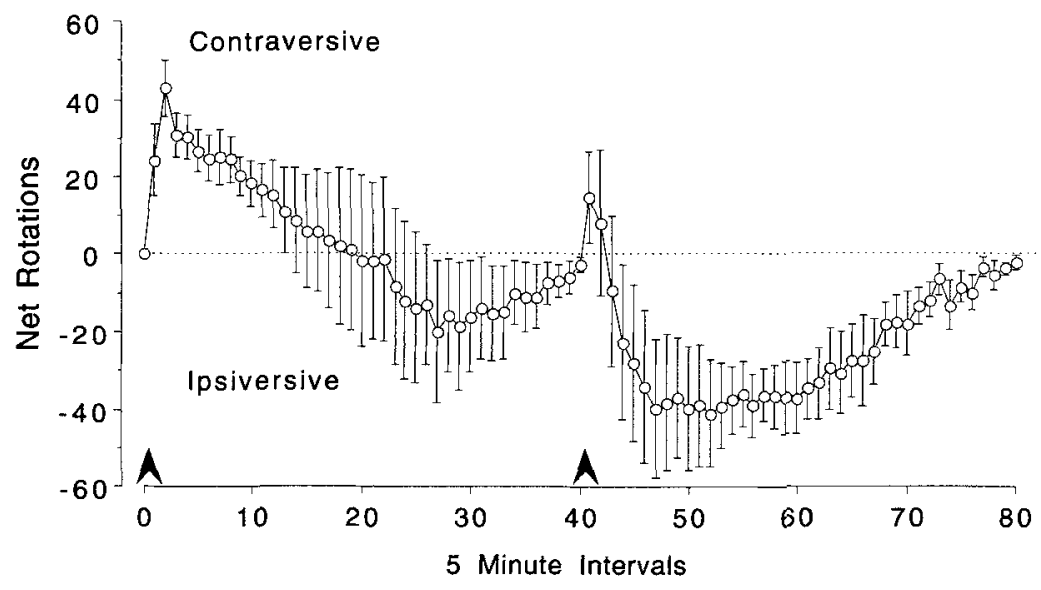

Fig. 5. The mean ( \pm SEM) number of net rotations per 5 min interval following two successive injections of $1.5 \mathrm{mg} / \mathrm{kg}$ of $d$-amphetamine $(\mathbf{n}=5$ ). Amphetamine was given at the time indicated by the arrowheads. Positive numbers were arbitrarily defined as rotations in the contraversive direction and negative numbers as rotations in the ip- siversive direction. Note that following the first injection of amphetamine all animals turned predominantly in the contraversive direction, whereas following the second injection all animals turned predominantly in the ipsiversive direction.
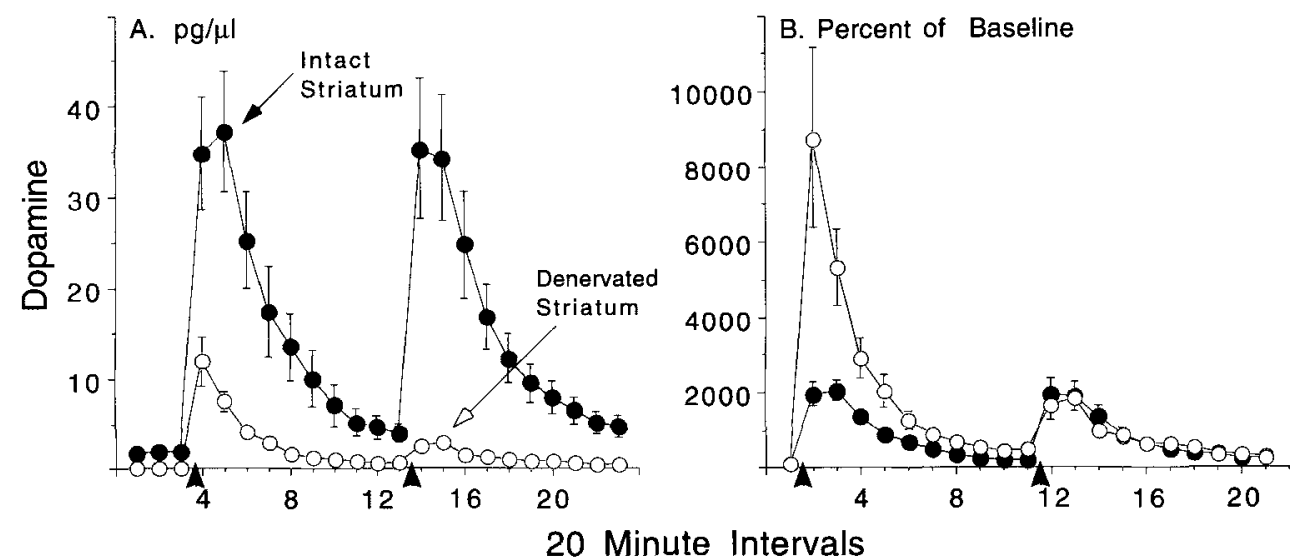

Fig. 6. The mean ( \pm SEM) concentration of DA in successive $20 \mathrm{~min}$ fractions of striatal dialysate obtained simultaneously from the intact and denervated striata of rats tested 4 days following a unilateral 6-OHDA lesion $(n=5)$. Samples were obtained both before (first 3 intervals) and following two successive injections of $1.5 \mathrm{mg} / \mathrm{kg}$ of $d$-amphetamine. Amphetamine was administered at the time indicated by the arrowheads. A: DA expressed in $\mathrm{pg} / \mu \mathrm{l}$. In the intact striatum, the first and second injection of amphetamine induced an equivalent large increase in the concentration of DA (comparison of 1st vs. 2nd injection, two-way ANOVA, non-significant). In the denervated striatum, the first injection of amphetamine produced a smaller, but highly significant, increase in extracellular DA. The second injection of amphetamine produced very little DA release in the denervated striatum, relative to either the intact striatum, or that seen on the denervated side following the first injection (two-way ANOVA comparing 1st vs. 2nd injection, $F_{\text {ingction }}=14.3, \quad P<0.004, \quad F_{\text {, }}$, $P<0.001$ ). B: DA expressed as a percent of baseline. The decrease in the magnitude of DA release in the denervated striatum between the first and second injections of amphetamine is especially evident when the data are plotted as a percent of baseline (Fig. 6B). lowing the first exposure to amphetamine, and primarily ipsiversive rotation occurred with subsequent injections of amphetamine.

It is interesting to speculate that the residual pool of DA seen on Day 4 may be contained in structures somewhat analogous to "synaptosomes." In this experiment 6-OHDA was infused near the DA cell bodies, and the soma and axons of most DA cells may have degenerated by Day 4 post-lesion. This may leave, however, a few isolated DA terminals in the striatum that have not yet degenerated. These "in vivo synaptosomes" may con- tain DA, but would not show spontaneous impulse-dependent DA release, because there is no soma to initiate impulses, and no axon to conduct them. Amphetamine may release DA, however, because the DA transporter is still functional, allowing for accelerative exchangediffusion (Fischer and Cho, 1979). This would explain why on Day 4 post-lesion spontaneous rotational behavior is in the ipsiversive direction, but amphetamineinduced rotation in the contraversive direction. Whether other ion channels are operative, as in synaptosomes, is not known, but if they are, the local applica- 


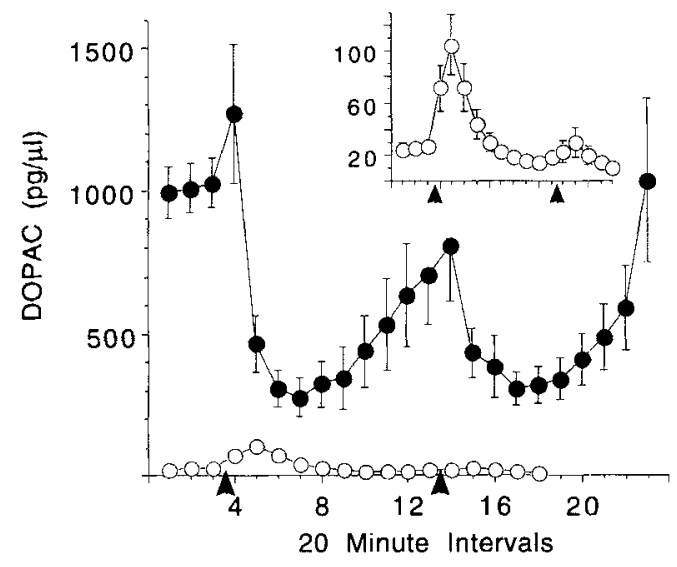

Fig. 7. The mean ( \pm SEM) concentration of DOPAC in successive 20 min fractions of striatal dialysate $(\mathrm{pg} / \mathrm{\mu l}$ ) obtained simultaneously from the intact (closed circles) and denervated striata (open circles) of rats tested 4 days following a unilateral 6-OHDA lesion $(n=5)$. Samples were obtained both before (first 3 intervals) and following two successive injections of $1.5 \mathrm{mg} / \mathrm{kg}$ of $d$-amphetamine. Amphetamine was administered at the time indiated by the arrowheads. The 6-OHDA lesion resulted in a marked decrease in the basal concentration of DOPAC in dialysate (compare basal intact side to basal denervated side values). In the intact striatum, amphetamine produced the expected decrease in extracellular DOPAC following both the first and second treatments. In the denervated striatum, the first injection of amphetamine produced a small, but highly significant, increase in DOPAC (one-way ANOVA, $F=13.9, P<0.001$ ). In contrast, the second injection of amphetamine did not produce a comparable increase in DOPAC $(P<0.01)$. The values for DOPAC for just the denervated side are replotted in the inset, with an expanded vertical scale, to better illustrate the magnitude of the amphetamine-induced increase in DOPAC. Values for intervals 19-23 are not given for the denervated striatum because DOPAC was nondetectable in too many samples to calculate meaningful averages.

tion of other releasing agents should also evoke DA release. This pool of DA may not be renewable, however, because without a cell body the enzymes critical for neurotransmitter synthesis, and the proteins required for neurotransmission, could not be replenished. Ultrastructurally, this pool of DA may be located in 'boutons of the "dense" type' described by Hökfelt and Ungerstedt (1969), which are most numerous 2-4 days after a 6-OHDA lesion.

A final interesting observation in the present study was the amphetamine-induced increase in the concentration of DOPAC in the denervated striatum seen 4 days post-lesion. Amphetamine normally produces a decrease in extracellular DOPAC, as seen here in control animals and in the intact striatum of animals with a 6-OHDA lesion. Amphetamine is thought to decrease DOPAC because it depletes a cytoplasmic pool of newly synthesized DA that is normally subject to degradation by intraneuronal monoamine oxidase (Zetterström et al., 1988). The amount of DOPAC formed from released DA that is taken back up into the presynaptic terminal, and then metabolized, is thought to be insignificant normally, relative to the amount of DOPAC produced intraneuronally, independent of release. This is why DOPAC usually is considered to be a poor indicator of DA release (Wood and Altar, 1988). In the denervated striatum, however, the contribution of DOPAC formed from released DA may be relatively large, because most cytoplasmic DOPAC is lost when the DA terminals degenerate. Thus, in the denervated striatum the metabolism of released DA may be "unmasked" in a sense, and under these conditions the extracellular concentration of DOPAC reflects DA release.

In conclusion, we suggest that the seemingly paradoxical reversal in the direction of amphetamine-induced rotational behavior between 4 and 8 days after a unilateral 6-OHDA lesion is not inconsistent with the traditional rotational behavior model (Ungerstedt, 1971a,b; Ungerstedt and Arbuthnott, 1970). Our results suggest that on Day 4 post-lesion the amount of DA released by amphetamine in the denervated striatum is sufficient to produce greater DA receptor stimulation on that side, because this DA acts on supersensitive DA receptors. By Day 8 post-lesion animals reverse their direction of amphetamine-induced rotational behavior, because now amphetamine fails to release any DA in the denervated striatum, and therefore, there is greater DA receptor stimulation on the intact side, where amphetamine does release DA.

\section{ACKNOWLEDGMENTS}

This research was supported by a grant to T.E.R. from the National Parkinson Foundation (U.S.A.) and to I.Q.W. from the Medical Research Council of Canada.

\section{REFERENCES}

Altar, C.A., Marien, M.R., and Marshall, J.F. (1987) Time course of adaptations in dopamine biosynthesis, metabolism, and release following nigrostriatal lesions: Implications for behavioral recovery from brain injury. J. Neurochem., 48:390-399.

Altar, C.A., O'Neil, S., and Marshall, J.F. (1984) Sensorimotor impairment and elevated levels of dopamine metabolites in the neostriatum occur rapidly after intranigral injection of 6-hydroxydopamine or gamma-hydroxybutyrate in awake rats. Neuropharmacology, 23: $309-318$.

Carey, R.J. (1992) Factors in amphetamine-induced contralateral rotation in the unilateral 6-OHDA lesion rat model during the firstweek postoperative: Implications for neuropathology and neural grafting. Brain Res., 570:11-20.

Castañeda, E., Whishaw, I.Q., and Robinson, T.E. (1990) Changes in striatal dopamine neurotransmission assessed with microdialysis following recovery from a bilateral 6-OHDA lesion: Variation as a function of lesion size. J. Neurosci., 10:1847-1854.

Costall, B., Marsden, C.D., Naylor, R.J., and Pycock, C.J. (1976) The relationship between striatal and mesolimbic dopamine dysfunction and the nature of circling responses following 6-hydroxydopamine and electrolytic lesions of the ascending dopamine systems of rat brain. Brain Res., 118:87-113.

Doucet, G., Descarries, L., and Garcia, S. (1986) Quantification of the dopamine innervation in adult rat neostriatum. Neuroscience, 19: $427-445$.

Ewing, A.G., and Wightman, R.M. (1984) Monitoring the stimulated release of dopamine with in vivo voltammetry. II. Clearance of released dopamine from extracellular fluid. J. Neurochem., 43:570577.

Fischer, J.F., and Cho, A.K. (1979) Chemical release of dopamine from striatal homogenates: Evidence for an exchange diffusion model. J. Pharmacol. Exp. Ther., 208:203-209.

Heffner, T.F., Hartman, J.A., and Seiden, L.S. (1980) A rapid method for the regional dissection of the rat brain. Pharmacol. Biochem. Behav, 13:453-456. 
Hökfelt, T., and Ungerstedt, U. (1969) Electron and fluorescence microscopical studies on the nucleus caudatus putamen of the rat after unilateral lesions of ascending nigro-neostriatal dopamine neurons. Acta Physiol. Scand., 76:415-426

Hökfelt, T., and Ungerstedt, U. (1973) Specificity of 6-hydroxydopamine induced degeneration of central monoamine neurones: An elec tron and fluorescence microscopic study with special reference to intracerebral injection on the nigrostriatal dopamine system. Brain Res., 60:269-297.

Keller, R.W., Jr, Kuhr, W.G., Wightman, R.M., and Zigmond, M.J. (1988) The effect of L-dopa on in vivo dopamine release from nigrostriatal bundle neurons. Brain Res., 447:191-194.

Kuczenski, R., and Segal, D. (1989) Concomitant characterization of behavioral and striatal neurotransmitter response to amphetamine using in vivo microdialysis. J. Neurosci., 9:2051-2065.

Lynch, M.R., and Carey, R.J. (1989) Amphetamine-induced rotation reveals post $6-\mathrm{OHDA}$ lesion neurochemical reorganization. Behav. Brain Res., 32:69-74.

Marshall, J.F., and Ungerstedt, U. (1977) Supersensitivity to apomorphine following destruction of the ascending dopamine neurons: Quantification using the rotational model. Eur. J. Pharmacol., 41: 361-367.

McFarlane, D.K., Martonyi, B.J., and Robinson, T.E. (1992) An inexpensive automated system for the measurement of rotational behavior in small animals. Behav. Res. Methods Inst. Computers, 24:414419.

Mintz, M., Douglas, R.J., Tomer, R., de Villiers, A.S., and Kellaway, L. (1986) Transient contralateral rotation following unilateral substantia nigra lesion reflects susceptibility of the nigrostriatal system to exhaustion by amphetamine. Life Sci., 39:69-76.

Mishra, R.K., Marshall, A.M., and Varmuza, S.L. (1980) Supersensitivity in rat caudate nucleus: effects of 6 -hydroxydopamine on the time course of dopamine receptor and cyclic AMP changes. Brain Res., 200:47-57.

Moghaddam, B., and Bunney, B.S. (1989) Ionic composition of microdialysis perfusing solution alters the pharmacological responsiveness and basal outflow of striatal dopamine. J. Neurochem., 53:652-654.

Neve, KA Altar, C.A. Wong, C.A, and Marshall, J.F. (1984) Quantitative analysis of $[3 \mathrm{H}]$ spiroperidol binding to rat forebrain sections: plasticity of neostriatal dopamine receptors after nigrostriatal injury. Brain Res., 302:9-18.

Neve, K.A., Kozlowski, M.R, and Marshall, J.F. (1982) Plasticity of neostriatal dopamine receptors after nigrostriatal injury: relationship to recovery of sensorimotor functions and behavioral supersensitivity. Brain Res., 244:33-44.

Oberlander, C., Dumont, C., and Boissier, J.R. (1980) Time course of apomorphine-induced circling behaviour after striatal dopamine receptor denervation. Eur. J. Pharmacol., 62:107-110.

Paxinos, G., and Watson, C. (1986) The Rat Brain in Stereotaxic Coordinates. Raven Press, New York.
Robinson, T.E., Becker, J.B., Young, E.A., Akil, H, and Castañeda, E. (1987) The effects of footshock stress on regional brain dopamine metabolism and pituitary beta-endorphin release in rats previously

sensitized to amphetamine. Neuropharmacology, 26:679-691.
Robinson, T.E., and Camp, D.M. (1991) The feasibility of repeated microdialysis for within-subjects design experiments: Studies on the mesostriatal dopamine system. In: Microdialysis in the Neurosciences. T.E. Robinson and J.B. Justice Jr., eds. Elsevier, Amsterdam, pp. 189-234.

Robinson, T.E., Castan̄eda, E., and Whishaw, I.Q. (1990) Compensatory changes in striatal dopamine neurons following recovery from injury induced by 6-OHDA or methamphetamine: $A$ review of evidence of microdialysis studies. Can. J. Psychol., 44:253-275.

Robinson, T.E., and Whishaw, I.Q. (1988) Normalization of extracellular dopamine in striatum following recovery from a partial unilateral 6-OHDA lesion of the substantia nigra: A microdialysis study in freely moving rat. Brain Res., 450:209-224.

Staunton, D.A., Wolfe, B.B., Groves, P.M., and Molinoff, P.B. (1981) Dopamine receptor changes following destruction of the nigrostriatal pathway: Lack of a relationship to rotational behavior. Brain Res., 211:315-327.

Ungerstedt, U. (1971a) Postsynaptic supersensitivity after 6-hydroxydopamine induced degeneration of the nigro-striatal dopamine system. Acta Physiol. Scand., 367:69-93.

Ungerstedt, U. (1971b) Striatal dopamine release after amphetamine or nerve degeneration revealed by rotational behaviour. Acta Physiol. Scand. 367:49-68.

Ungerstedt, U., and Arbuthnott, G.W. (1970) Quantitative recording of rotational behavior in rats after 6-hydroxy-dopamine lesions of the nigrostriatal dopamine system. Brain Res., 24:485-493.

van Horne, C., Hoffer, B.J., Stromberg, I., and Gerhardt, G.A. (1992) Clearance and diffusion of locally applied dopamine in normal and 6-hydroxydopamine-lesioned rat striatum. J. Pharmacol. Exp. Ther., 263:1285-1292.

Wightman, R.M. and Zimmerman, J.B. (1990) Control of dopamine extracellular concentration in rat striatum by impulse flow and uptake. Brain Res. Rev., 15:135-144.

Wood, P.L., and Altar, C.A. (1988) Dopamine release in vivo from nigrostriatal, mesolimbic, and mesocortical neurons: utility of 3-methoxytyramine measurements. Pharmacol. Rev., 40:163-187.

Zetterström, T., Sharp, T., Collin, A.K., and Ungerstedt, U. (1988) In vivo measurement of extracellular dopamine and DOPAC in rat striatum after various dopamine-releasing drugs; implications for the origin of extracellular DOPAC. Eur, J. Pharmacol,, 148:327334.

Zigmond, M.J., Abercrombie, E.D., Berger, T.W., Grace, A.A., and Stricker, E.M. (1990) Compensations after lesions of central dopaminergic neurons: Some clinical and basic implications. Trends Neurosci., 13:290-296. 